Check for updates

Cite this: Phys. Chem. Chem. Phys., 2018, 20, 23233

Received 26th May 2018, Accepted 17th August 2018

DOI: $10.1039 / c 8 c p 03345 e$

rsc.li/pccp

\section{Lithium permeation within lithium niobate multilayers with ultrathin chromium, silicon and carbon spacer layers $\dagger$}

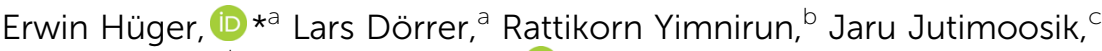 \\ Jochen Stahn ${ }^{d}$ and Amitesh Paul (iD) ${ }^{e}$
}

\begin{abstract}
Li permeation through ultrathin $\mathrm{Cr}, \mathrm{Si}$ and $\mathrm{C}$ layers and interfaces is of interest in the optimization of lithium ion batteries with respect to the control of $\mathrm{Li}$ flux. Twenty-one $\mathrm{LiNbO}_{3}$ layers $(9 \mathrm{~nm})$, which serve as solid state Li reservoirs, were sputter deposited in an alternating sequence of enriched ${ }^{6} \mathrm{Li}$ or ${ }^{7} \mathrm{Li}$ isotope fractions spaced with $(8 \mathrm{~nm})$ thin $\mathrm{Cr}, \mathrm{Si}$ and $\mathrm{C}$ layers. The $\mathrm{Li}$ isotope contrast was used to measure $\mathrm{Li}$ permeation using depth profiling by secondary ion mass spectrometry and neutron reflectometry on a nanometer scale. Extremely low Li permeation for $\mathrm{Cr}$ and $\mathrm{Si}$ at room temperature exemplifies the effective blocking of Li movement at least for five years. However, Li permeation through $\mathrm{C}$ layers was found to be faster than through $\mathrm{Cr}$ and Si layers. With temperature, the $\mathrm{Li}$ permeation is enhanced through $\mathrm{Cr}$ as compared to that through Si layers. Furthermore, material characterisation shows amorphous $\mathrm{LiNbO}_{3}$, $\mathrm{C}$ and Si layers and polycrystalline Cr layers (with $80 \%$ elemental bcc chromium and 20\% chromium-oxide situated at $\mathrm{Cr} / \mathrm{LiNbO}_{3}$ interfaces). Annealing in air at $100{ }^{\circ} \mathrm{C}(373 \mathrm{~K})$ does not oxidize the $\mathrm{Cr}$ layers any further. A stress of $12 \mathrm{GPa}$, which was measured in $\mathrm{Cr}$ spacer layers at room temperature, remains unchanged upon annealing. The origin of a weak ferromagnetic order measured at room temperature (300 K) was attributed to some traces of $\mathrm{Cr}$ and $\mathrm{Si}$ inside $\mathrm{LiNbO}_{3}$.
\end{abstract}

\section{Introduction}

Artificial multilayers ${ }^{1,2}$ present an opportunity to design stable structures with non-equilibrium properties different from the bulk forms of their components. ${ }^{3-12}$ The more different the properties of alternating layers are, the more surprising can be the properties of a whole multilayer. The proximity of an electronic insulator to a pure electronic conductor can lead to spatially separated ultrafast (dual) transport pathways of electrons and ions with ionic diffusion coefficients higher than

\footnotetext{
${ }^{a}$ Institute of Metallurgy, Microkinetics Group, Clausthal University of Technology, Robert-Koch-Str. 42, D-38678 Clausthal Zellerfeld, Germany.

E-mail: erwin.hueger@tu-clausthal.de

${ }^{b}$ School of Energy Science and Engineering, Vidyasirimedhi Institute of Science and Technology, Wang Chan Valley, Rayong 21210, Thailand

${ }^{c}$ Department of Physics, Faculty of Science, Naresuan University, Phitsanulok, 65000, Thailand

${ }^{d}$ Laboratory for Neutron Scattering and Imaging, Paul-Scherrer-Institut, CH-5232 Villigen PSI, Switzerland

${ }^{e}$ Technische Universität München, Physik Department E21, Lehrstuhl für Neutronenstreuung, James-Franck-Straße 1, D-85748 Garching, Germany

$\dagger$ Electronic supplementary information (ESI) available: It contains a literature survey, details on multilayer preparation and detailed analysis of microscopy, SIMS, NR, GIXRD, FTIR, Raman scattering and EXAFS data, and last but not least a discussion on magnetic behaviour. See DOI: 10.1039/c8cp03345e
}

in liquids. ${ }^{12}$ Therefore, synergistic, ultrafast mass storage and consequent removal in artificially mixed materials can appear. ${ }^{12}$ Obviously, most of the generated properties stem from the proximity of different materials in a multilayer, i.e. from interfaces. ${ }^{10-13}$

Superlattices possess a large number of interfaces, enhancing possible usage of interface generated properties. For example, space charge layers can appear on Schottky contact types of interfaces which strongly affect nanoionics and charge transport phenomena. ${ }^{14-36}$ On Schottky-contact like interfaces, the electronic band structure is locally disturbed by band bending. Furthermore, quantum size effects can appear in ultrathin layers, which also change the electronic band structure according to the quantum well state requirements. ${ }^{37}$ The changes in band structure can change the density of states at the Fermi energy. This can generate properties different to those known for the materials of the constituent layers. ${ }^{38-42}$

In general, oxide and non-oxide materials possess a strong contrast in properties. Most prominent oxides, such as silica and lithium niobate $\left(\mathrm{LiNbO}_{3}\right)$, are insulators, whereas typical non-oxide materials, such as d-band metals (e.g. Cr), are good electrical conductors. This work reports on the fabrication and characterization of multilayers which combine $\mathrm{LiNbO}_{3}$ with chromium, silicon and carbon layers. It is shown that laminar structures of alternating ultrathin layers of amorphous $\mathrm{LiNbO}_{3}$ 
and $\mathrm{Cr}$, Si and $\mathrm{C}$ material are stable and enable the measurement of $\mathrm{Li}$ permeation through these layers and interfaces which is of interest for lithium ion batteries with respect to the control of Li flux. The knowledge of the Li permeation strength enables understanding of the mechanism and kinetics of electrochemical Li storage in electrodes. ${ }^{80}$

Coating of $\mathrm{Li}$ ion battery electrodes with thin films ${ }^{43-47}$ is a strategy to improve the operation, such as the lifespan of next generation lithium-ion batteries for high power application. Beside carbon, ${ }^{43}$ chromium ${ }^{44-47}$ coating is also a route to produce operable Li-ion batteries with negative electrodes possessing $\mathrm{Si}$ as the active material. Silicon has the highest known gravimetric capacity to store electrical energy ( $\mathrm{Li}$ ions) up to the $\mathrm{Li}_{4.4} \mathrm{Si}$ alloy. ${ }^{48,49}$ Unfortunately, at such a huge $\mathrm{Li}$ storage the Li-Si active material expands by nearly $400 \%$. Research using silicon materials has experienced that cycling pulverizes the silicon electrode, rapidly reducing its overall capacity by silicon delamination from the current collector. To avoid this deficiency, Cr-coated nanosilicon (e.g. Si nano-powder) cells, for example, are found to be superior to uncoated cells for battery operation. ${ }^{46,47}$ Moreover, it is claimed that the coating of electrodes with $\mathrm{Cr}$ enables the storage of a larger amount of $\mathrm{Li}$ in the active material of the battery. ${ }^{47}$ Furthermore, the battery operation characteristics were found to be enhanced when the positive electrode is also coated with $\mathrm{Cr}^{50}$ Recently, ${ }^{43,45}$ it was shown that a multilayer architecture comprising of $\mathrm{C} / \mathrm{Si}^{43}$ and $\mathrm{Cr} / \mathrm{Si}^{45}$ multilayers is a novel strategy for addressing the extreme challenges associated with high energy storage materials in Li-ion batteries. Chromium does not store Li, i.e. it does not lithiate. In the lithiation and delithiation process of $\mathrm{Cr}$ (and $\mathrm{C}$ ) coated electrodes (Si nanopowder, and $\mathrm{Cr} / \mathrm{Si}$ and $\mathrm{C} / \mathrm{Si}$ multilayers), Li has to permeate through the $\mathrm{Cr}$ (C) spacer layers in order to be stored or removed from the active materials of electrodes.

For energy devices such as batteries, there is a huge effort to reduce the inactive material of a battery by using ultrathin layers. Chromium layers with thicknesses in between 2 and $15 \mathrm{~nm}$ are used to increase the adhesion of the metallic current collector (such as $\mathrm{Au}, \mathrm{Cu}$, and $\mathrm{Pt}$ films) to the packaging support (e.g. ceramic materials). ${ }^{51-54}$ The Cr layer is in between the current collector and the packaging support and is also in between the current collector and the active (e.g. Si) material. ${ }^{53}$ There is a stringent condition which dictates that Li should not penetrate the current collector (and the Cr layer) so that it does not reach the packaging support (glass silica) where it eventually gets lost. The capacity loss seen upon cycling lithium ion batteries (LIBs) was recently attributed to diffusive loss of $\mathrm{Li}$ in current collectors. ${ }^{83,84} \mathrm{Li}$ that has reached the current collector (or the Cr layer) is no more in an ionic state. In that case, the $\mathrm{Li}$ permeation happens only by Li diffusion without an electrical driving force. Thereby, experiments of $\mathrm{Li}$ permeation through thin Cr layers without an electrical driving force are necessary. Such Li permeation experiments are presented in this work.

With regards to size effects on charge transport, one has to mention that the electronic industry worldwide possess a pressing need to reduce the dimensions of integrated circuit components to below $10 \mathrm{~nm}^{55}$ Unfortunately, this trend is coming to stagnancy because the resistivity of the transistor interconnects increases with shrinking dimensions. ${ }^{55}$ The capability of nano-sized metals to conduct electronic charge decreases if the shrinking dimension is in the nanoscale regime (e.g. below $38 \mathrm{~nm}$ for copper). ${ }^{55}$ The aim of the present work is (i) to investigate the capability of nano-sized metal to conduct $\mathrm{Li}$ and (ii) to analyse the properties of the material through which Li permeation can be measured. Recently, Hüger et al. introduced multilayers which combine amorphous $\mathrm{LiNbO}_{3}$ layers with $\mathrm{Si}$ spacer layers (i.e. $\left[\mathrm{LiNbO}_{3} / \mathrm{Si}\right]$ multilayers) to measure Li permeation through Si layers. ${ }^{56}$ In this work we provide additional insights into this new class of multilayers and $\mathrm{LiNbO}_{3}$ layers spaced by ultrathin chromium and carbon layers. These results are compared to Li conductivity through ultrathin Si layers. In all cases, Li permeation was measured without applying an electrical driving force.

\section{Materials and methods}

Multilayers as sketched in Fig. 1 were deposited using an ionbeam coater (IBC 681) from Gatan, Inc. (Pleasanton, CA, USA). The depositions were performed at room temperature. ${ }^{2}$ The multilayer samples were stored in air and at room temperature (300 K). Annealing was performed at 1 mbar using a drying furnace. Synchrotron extended X-ray absorption fine structure spectroscopy (EXAFS) measurements were performed in situ during $\mathrm{Li}$ permeation at $100{ }^{\circ} \mathrm{C}(373 \mathrm{~K})$ at SRLI, Thailand. All other measurements were performed at room temperature.

There are not many measurement techniques sensitive to light elements such as lithium. We apply two techniques with proper sensitivity for lithium (also isotope) detection, neutron reflectometry $(\mathrm{NR})^{85}$ and secondary ion mass spectrometry (SIMS). ${ }^{86}$ SIMS was applied to determine primarily the Li isotope depth profile of the multilayer. Furthermore, profound investigations were performed also with X-ray reflectivity (XRR), grazing incidence X-ray diffraction (GI-XRD), Fourier transform infrared spectroscopy (FTIR), Raman scattering, and EXAFS with details given in the ESI accompanying this work. ${ }^{2}$ Magnetisation curves were measured using a superconducting quantum interference device (SQUID) from Quantum Design (MPMS-XL).

\section{Results and discussion}

Fig. 1a sketches the basic structure used for the investigations of Li transport through thin spacer layers. It consists of a triple layer form of ${ }^{7} \mathrm{LiNbO}_{3} /$ spacer-layer $/{ }^{6} \mathrm{LiNbO}_{3}$ with single layer
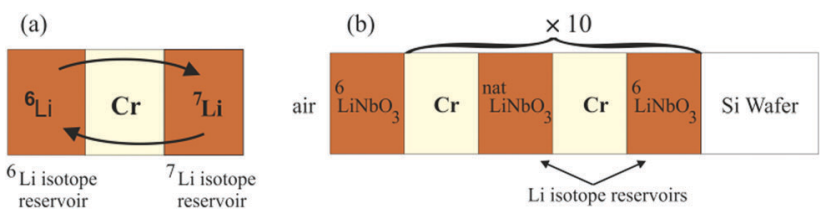

Fig. 1 (a) Basic principle of the experimental arrangement: two Li isotope reservoir layers are spaced by a $\mathrm{Cr}$ (or Si or C) layer. (b) Sketch of the multilayer produced for NR measurements. 
thicknesses of up to $10 \mathrm{~nm}$. Here, two isotope enriched lithium niobate layers are placed adjacent to a $\mathrm{Cr}$ ( $\mathrm{Si}$ or $\mathrm{C}$ ) layer. The lithium niobate layers serve as solid state Li reservoirs. Annealing leads to a mutual exchange of $\mathrm{Li}$ isotopes through the spacer layers and adjacent interfaces by $\mathrm{Li}$ permeation and thus to a leveling of the isotope fractions. The Li kinetics is obtained by measuring the fraction of ${ }^{6} \mathrm{Li}$ and ${ }^{7} \mathrm{Li}$ isotopes in the $\mathrm{Li}$ reservoirs. The multilayer sketched in Fig. $1 \mathrm{~b}$ with twenty $\left(\mathrm{LiNbO}_{3} /\right.$ spacer-layer) double layers was used for NR experiments. ${ }^{2}$ Visualization of the multilayer stack with up to $10 \mathrm{~nm}$ thin layers is achieved even with optical microscopy as presented in the ESI. ${ }^{2}$

\subsection{Atomic and isotope depth profiling performed with SIMS}

Fig. 2 and 3 represent the ${ }^{6} \mathrm{Li} /{ }^{7} \mathrm{Li}$ isotope contrast in the $\mathrm{LiNbO}_{3}$ layers of the multilayer with $\mathrm{Si}, \mathrm{Cr}$ and $\mathrm{C}$ spacer layers as measured by SIMS depth profiling. Astounding periodic SIMS signals were measured in the depth profiles for the ML with Si and $\mathrm{Cr}$ spacer layers $\left(\mathrm{ESI}^{2}\right)$. The recorded $\mathrm{Li}^{+}$SIMS signals are extremely strong. An $\left(\mathrm{O}_{2}{ }^{+}, 5 \mathrm{keV}\right)$ primary ion beam was used for the SIMS measurements presented in the main article. Extensive SIMS data are presented in the ESI. ${ }^{2}$ A discussion about the destructive nature of SIMS, i.e. the sputtering process, on the depth profiles is also given. ${ }^{2}{ }^{6} \mathrm{Li}$ (and ${ }^{7} \mathrm{Li}$ ) isotope fraction can be obtained from the SIMS signals by the following fraction of SIMS intensities

$$
\chi_{6} \mathrm{Li}=\frac{I_{\mathrm{SLi}}^{6} \mathrm{Li}}{I_{\mathrm{SIMS}}^{6}+I_{\mathrm{SIMS}}^{7 \mathrm{Li}}} ; \quad \chi^{7} \mathrm{Li}=\frac{I_{\mathrm{SLi}}^{7} \mathrm{Li}}{I_{\mathrm{SIMS}}^{6}+I_{\mathrm{SIMS}}^{7 \mathrm{Li}}}=1-\chi^{6} \mathrm{Li}
$$

where $I_{\mathrm{SIMS}}^{6 \mathrm{Li}}$ and $I_{\mathrm{SIMS}}^{7} \mathrm{Li}$ are the SIMS intensities measured for the ${ }^{6} \mathrm{Li}$ and ${ }^{7} \mathrm{Li}$ masses, respectively. The obtained $\mathrm{Li}$ isotope fraction are presented in Fig. 3. A strong modulation of the
Li isotope fraction is measured by SIMS in as-deposited multilayers with Si (Fig. 3a and b) and Cr (Fig. 3c and d) spacer layers.

\subsection{Li permeation at room temperature}

The influence of multilayer storage in air and room temperature for roughly 5 years is presented in Fig. 3 . The Li contrast in the ML with carbon spacer layers is diminished (Fig. 3f). The decrease of the ${ }^{6} \mathrm{Li}$ isotope fraction in the ${ }^{6} \mathrm{LiNbO}_{3}$ layers up to full isotope intermixing is given by (neglecting initial transition times) $)^{56,80}$

$$
\chi^{6} \mathrm{Li}=A+B \cdot \exp \left[-\frac{t}{\tau}\right]
$$

with

$$
A=\frac{\chi_{{ }^{6} \mathrm{Li}}^{0}-\phi_{{ }^{6} \mathrm{Li}}^{0}}{2} \text { and } B=\frac{\chi_{{ }^{\mathrm{Li}}}^{0}-\phi_{{ }^{6} \mathrm{Li}}^{0}}{2}
$$

where $\chi_{6}^{0} \mathrm{Li}$ and $\phi_{6}^{0} \mathrm{Li}$ are the ${ }^{6} \mathrm{Li}$ isotope fraction in the ${ }^{6} \mathrm{LiNbO}_{3}$ and the nat $\mathrm{LiNbO}_{3}$ layer at $t=0$, i.e. before the $\mathrm{Li}$ isotope intermixing appears. The quantity $\tau$ represents the timeconstant of the exponential decay function and is given by ${ }^{56,80}$

$$
\tau=\frac{1}{4} \cdot \frac{M_{\mathrm{Cr}}}{M_{\mathrm{LiNbO}_{3}}} \cdot \frac{\rho_{\mathrm{LiNbO}_{3}}}{\rho_{\mathrm{Cr}}} \cdot \frac{d_{\mathrm{Cr}} \cdot d_{\mathrm{LiNbO}_{3}}}{P}
$$

where $M_{\mathrm{Cr}}=51.99 \mathrm{~g} \mathrm{~mol}^{-1}$ is the molar mass of the spacer layer (the example given here is for Cr), $M_{\mathrm{LiNbO}_{3}}=146.85 \mathrm{~g} \mathrm{~mol}^{-1}$ is the molar mass of $\mathrm{LiNbO}_{3}, \rho_{\mathrm{LiNbO}_{3}}=4 \mathrm{~g} \mathrm{~cm} \mathrm{~cm}^{-3}$ is the mass density of the $\mathrm{LiNbO}_{3}$ layer, $\rho_{\mathrm{Cr}}=7 \mathrm{~g} \mathrm{~cm}^{-3}$ is the mass density of the spacer layer, $d_{\mathrm{Cr}}=8 \mathrm{~nm}$ is the thickness of the spacer layer, and $d_{\mathrm{LiNbO}_{3}}=9 \mathrm{~nm}$ is the thickness of the $\mathrm{LiNbO}_{3}$ reservoir layer. ${ }^{2}$ The mass densities and layer thicknesses were obtained from the NR measurements (described later, see also Table $\mathrm{S} 1$ of $\mathrm{ESI}^{2}$ ). The parameter $P$ represents the $\mathrm{Li}$
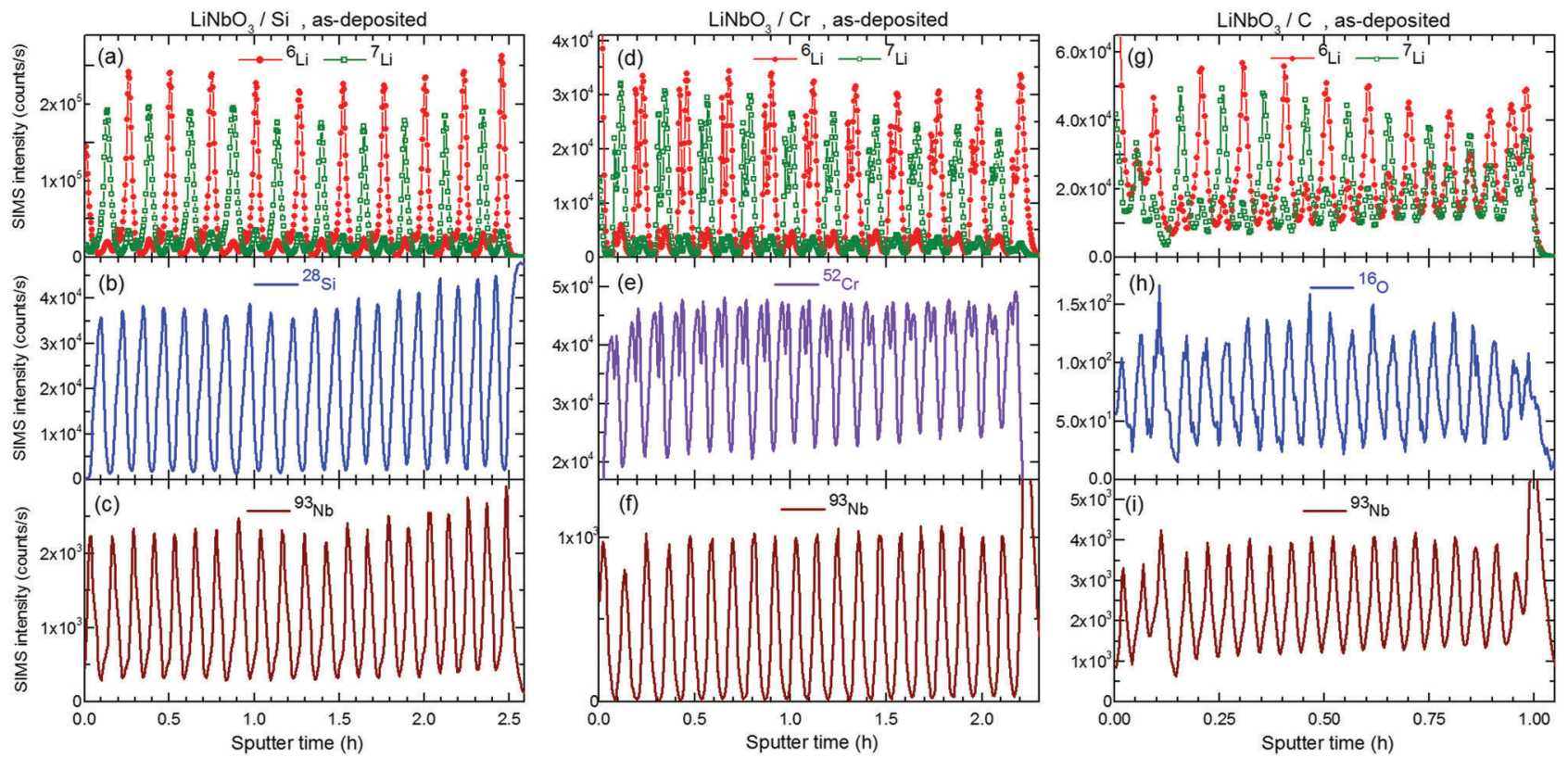

Fig. 2 SIMS depth profiles of (a, d and g) Li isotope, (b) ${ }^{28} \mathrm{Si},(e){ }^{52} \mathrm{Cr}$, (h) ${ }^{16} \mathrm{O}$, and (c, $\mathrm{f}$ and i) ${ }^{93} \mathrm{Nb}$ masses of the multilayer system with $\mathrm{Si}(\mathrm{a}-\mathrm{c}), \mathrm{Cr}(\mathrm{d}-\mathrm{f})$ and $\mathrm{C}(\mathrm{g}-\mathrm{i})$ spacer layers in the as-deposited state after 5 days of storage in air and room temperature (300 K). 

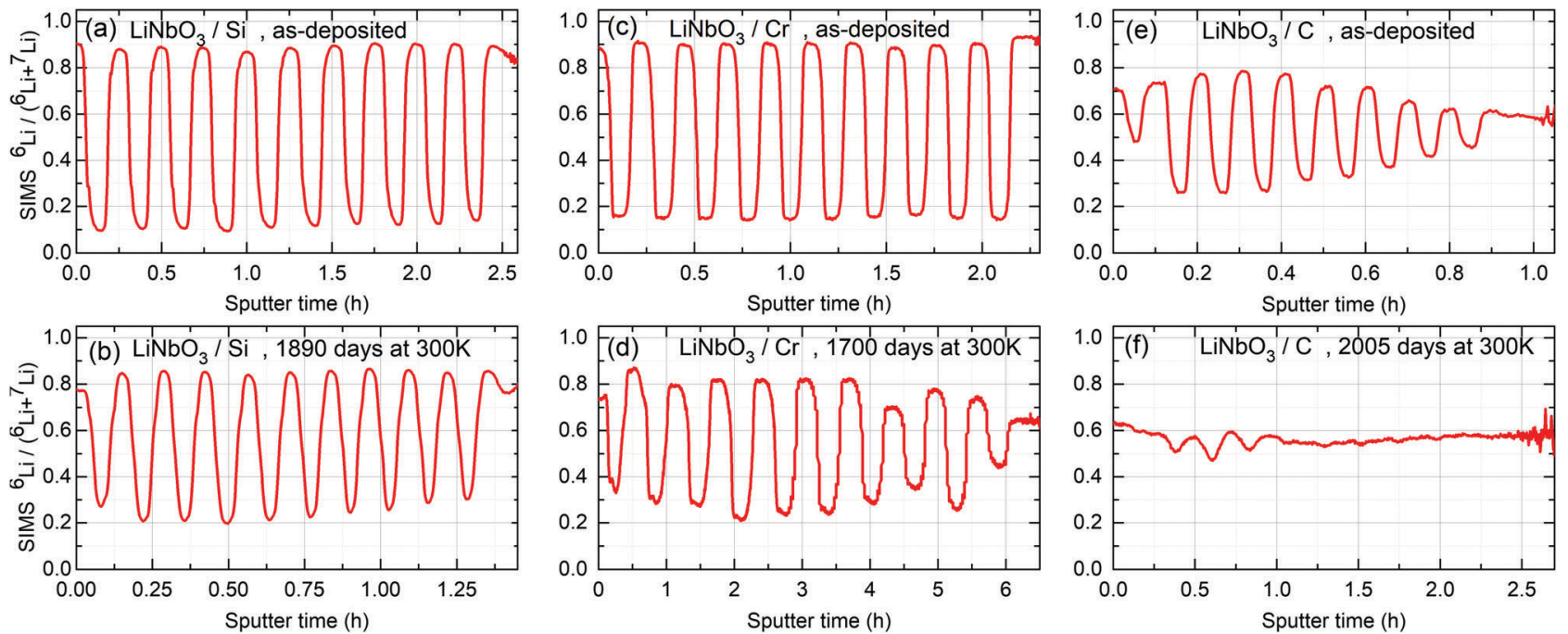

Fig. 3 Relative ${ }^{6}$ Li fraction as obtained from SIMS measurements on multilayers with $\mathrm{Si}$ (a and b), $\mathrm{Cr}$ (c and d) and $\mathrm{C}$ (e and f) spacer layers using eqn (1). (a, $\mathrm{C}$ and e) ${ }^{6} \mathrm{Li}$ fraction of the as deposited ML measured after 5 days of storage in air and room temperature (300 K) for the ML with Si (a), Cr (c) and C (e) spacer layers, respectively. (b, d and f) were measured after 1890, 1700 and 2005 days of storage in air and room temperature (300 K) for the ML with Si, $\mathrm{Cr}$ and $\mathrm{C}$ spacer layers, respectively. In displaying the isotope fraction, it is unnecessary to show the calculated values of both $\mathrm{Li} 6 /(\mathrm{Li} 6+\mathrm{Li}$ ) and $\mathrm{Li} 7 /(\mathrm{Li} 6+$ Li7), because if one of them is $\chi(t)$, the other is $1-\chi(t)$ (see eqn (1)).

permeability through the spacer layer defined as the product of the Li solubility $(S)$ and the Li diffusion coefficient $(D)$ in the spacer layer ${ }^{56,80}$

$$
P=S \cdot D
$$

The kinetics of $\mathrm{Li}$ isotope intermixing at room temperature through the carbon spacer layers enables the determination of the Li permeability. The Li isotope contrast $(K)$ in the Li isotope reservoirs is time dependent during Li permeation according to

$$
K(t)=\frac{\chi(t)-\chi_{\min }}{\chi_{\max }-\chi_{\min }}=\frac{\chi(t)-\chi(t \rightarrow \infty)}{\chi(t=0)-\chi(t \rightarrow \infty)}=\exp \left[-\frac{t}{\tau}\right]
$$

A fit of eqn (6) to the measured decrease of the Li isotope contrast (Fig. 4) determined the time constant of Li permeation through carbon layers to be $\tau=(989 \pm 200)$ days. $^{2}$ The permeability can be determined from eqn (4). A value of $P=(5 \pm 3) \times$ $10^{-26} \mathrm{~m}^{2} \mathrm{~s}^{-1}$ results for the $\mathrm{Li}$ flux through carbon layers at room temperature. Considering the upper limit of Li solubility in carbon to amount to $1 / 6 \mathrm{Li}$ atoms per $\mathrm{C}$ atom (corresponding to $\mathrm{LiC}_{6}$ ), a lower limit of Li diffusivity in the carbon spacer layers of $D=(3 \pm 2) \times 10^{-25} \mathrm{~m}^{2} \mathrm{~s}^{-1}$ is obtained for room temperature diffusion. This is an extremely low diffusivity value.

For the multilayer with $\mathrm{Si}$ and $\mathrm{Cr}$ spacer layers, the $\mathrm{Li}$ isotope contrasts are only marginally reduced (Fig. 3). Obviously, Li permeation through carbon layers is faster than through the $\mathrm{Si}$ and $\mathrm{Cr}$ layers.

Now, from the experiments performed on the multilayers with $\mathrm{Si}$ and $\mathrm{Cr}$ spacer layers stored at room temperature, one can suspect that the time constant $\tau$ for Li permeation is roughly 100 (or more) years. According to eqn (4), a roughly estimated Li permeability of $P \leq 2 \times 10^{-27} \mathrm{~m}^{2} \mathrm{~s}^{-1}$ is then obtained for the superlattice with $\mathrm{Si}$ and $\mathrm{Cr}$ spacer layers. This extremely low value corresponds to proper Li blocking.

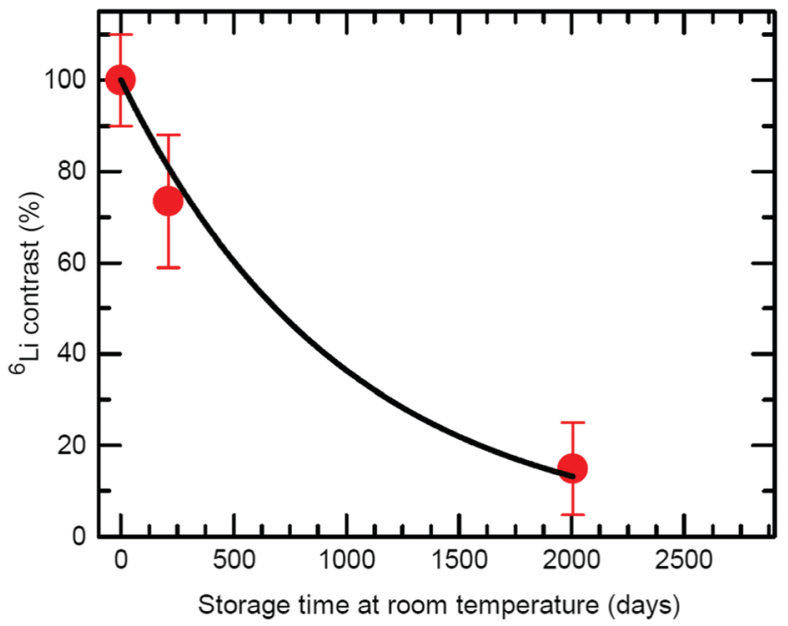

Fig. $4{ }^{6} \mathrm{Li}$ contrast (in percent) of the ${ }^{6} \mathrm{LiNbO}_{3}$ layers as a function of $\mathrm{ML}$ storage time at room temperature $(300 \mathrm{~K})$ as obtained from SIMS depth profiles performed on the ML with $C$ spacer layers. ${ }^{2}$ The line represent the fit of eqn (6) to measured data.

For silicon, the result contributes to an explanation why electrochemical lithiation of $\mathrm{Si}$ electrodes in LIBs takes place by a moving phase boundary separating a high lithiated Li-Si phase from a poor or non lithiated Si phase as discussed in ref. 80 .

A legitimate question that arises is whether $\mathrm{Li}$ transport is controlled by Li flux through the $\mathrm{LiNbO}_{3}$ reservoir layers or by $\mathrm{Li}$ permeation through the $\mathrm{Cr}$ and $\mathrm{Si}$ spacer layers. If $\mathrm{Li}$ permeation would be controlled by Li diffusion in the $\mathrm{LiNbO}_{3}$ reservoir layers, then the Li permeation strength should not be dependent on the spacer layer material. The faster $\mathrm{Li}$ permeation at room temperature measured for the ML with $\mathrm{C}$ (compared to $\mathrm{Cr}$ and $\mathrm{Si}$ ) spacer layers indicates that $\mathrm{Li}$ transport 
is controlled by the Li flux through the spacer layers. This finding is justified also by considering the Li diffusion coefficient in amorphous $\mathrm{LiNbO}_{3}$ measured by Rahn et al. ${ }^{57}$ for thin films stored at room temperature which amounts to $D=1 \times 10^{-18} \mathrm{~m}^{2} \mathrm{~s}^{-1}$. Considering the Li solubility in $\mathrm{LiNbO}_{3}$ to amount to 0.2 , a $\mathrm{Li}$ permeability of $P=2 \times 10^{-19} \mathrm{~m}^{2} \mathrm{~s}^{-1}$ is obtained for the $\mathrm{Li}$ flux through the $\mathrm{LiNbO}_{3}$ reservoir layers. This value is eight orders of magnitude larger than the measured Li flux in the multilayers. Hence, the Li diffusion inside the Li reservoirs is not responsible for the observed hindered Li isotope intermixing in Li reservoir layers. The Li blocking effect is due to the (e.g. Si and $\mathrm{Cr}$ ) spacer layers.

The slow Li permeation through $\mathrm{Si}$ and $\mathrm{Cr}$ spacer layers at room temperature does not solely mean that the Li diffusivity at room temperature is extremely low. According to eqn (5), the low Li permeability could stem from a very low solubility of $\mathrm{Li}$ in silicon and chromium material. The Li solubility in ultrathin amorphous $\mathrm{Si}$ and in nanocrystalline Cr layers is unknown, but it can be expected to be in the range of some ppm at room temperature. The phase diagram of $\mathrm{Li}-\mathrm{Si}$ in the crystalline form does not evidence any $\mathrm{Li}_{x} \mathrm{Si}$ phases for $x$ below $1.7 .^{58-67}$ The solubility of $\mathrm{Li}$ in crystalline silicon was measured to be very low. An extrapolation of the Li solubility in silicon versus inverse temperature $1 / T$ data $^{64-67}$ to room temperature gives the Li solubility in crystalline Si to be less than $1 \mathrm{ppm}$. The Li solubility in $95 \mathrm{~nm}$ thick amorphous Si layers was measured at temperatures of $240{ }^{\circ} \mathrm{C}$ and higher. ${ }^{80}$ An extrapolation to room temperature gives the Li solubility in thick amorphous Si layers to be extremely low, i.e., $3 \times 10^{-9} \mathrm{Li}$ per $\mathrm{Si}$ atom. ${ }^{80}$ In the case of chromium, Li does not alloy with it. ${ }^{68,69}$ There exist reports about only the solubility of $\mathrm{Cr}$ in liquid $\mathrm{Li} .{ }^{68,69}$ In similarity to $\mathrm{Si}$, one can expect that the solubility of $\mathrm{Li}$ in $\mathrm{Cr}$ is also very low. So, in order to induce considerable (measurable) Li permeation through the $\mathrm{Si}$ or $\mathrm{Cr}$ spacer layers we annealed the samples to enhance Li solubility and diffusivity. The measurements at elevated temperatures were performed non-destructively by neutron reflectometry.

\subsection{Atomic and isotope depth profiling performed with neutron scattering for $\mathrm{Li}$ permeation measurements}

Fig. 5 presents the NR pattern recorded from the ${ }^{6} \mathrm{Li} /{ }^{7} \mathrm{Li}$ isotope modulated $\mathrm{LiNbO}_{3}$ superlattice with $\mathrm{Cr}$ spacer layers, together with the NR simulation based on the Parratt formalism. Superlattice characteristics such as individual layer thicknesses, neutron scattering length density (SLD) and interlayer roughness corresponding to the best fit of Parratt32 simulation are listed in Table 1. The SLD depth profile is presented in Fig. 5b.

The Bragg peak located at $Q_{\mathrm{z}}=0.039 \AA^{-1}$ appears due to the double layer periodicity produced by the chemical contrast of $\mathrm{Cr}$ and $\mathrm{LiNbO}_{3}$ inside the superlattice.

The periodicity of the $\mathrm{Li}$ isotopes produces a four-layer periodicity $\left[\mathrm{Cr} /{ }^{6} \mathrm{LiNbO}_{3} / \mathrm{Cr} /{ }^{7} \mathrm{LiNbO}_{3}\right]$ in neutron scattering from the superlattice. Consequently, the Bragg peak located at $Q_{\mathrm{z}}=0.023 \AA^{-1}$ appears due to the four-layer periodicity produced by the $\mathrm{Li}$ isotope contrast inside the superlattice. In contrast to the SIMS measurements, NR does not give any hints
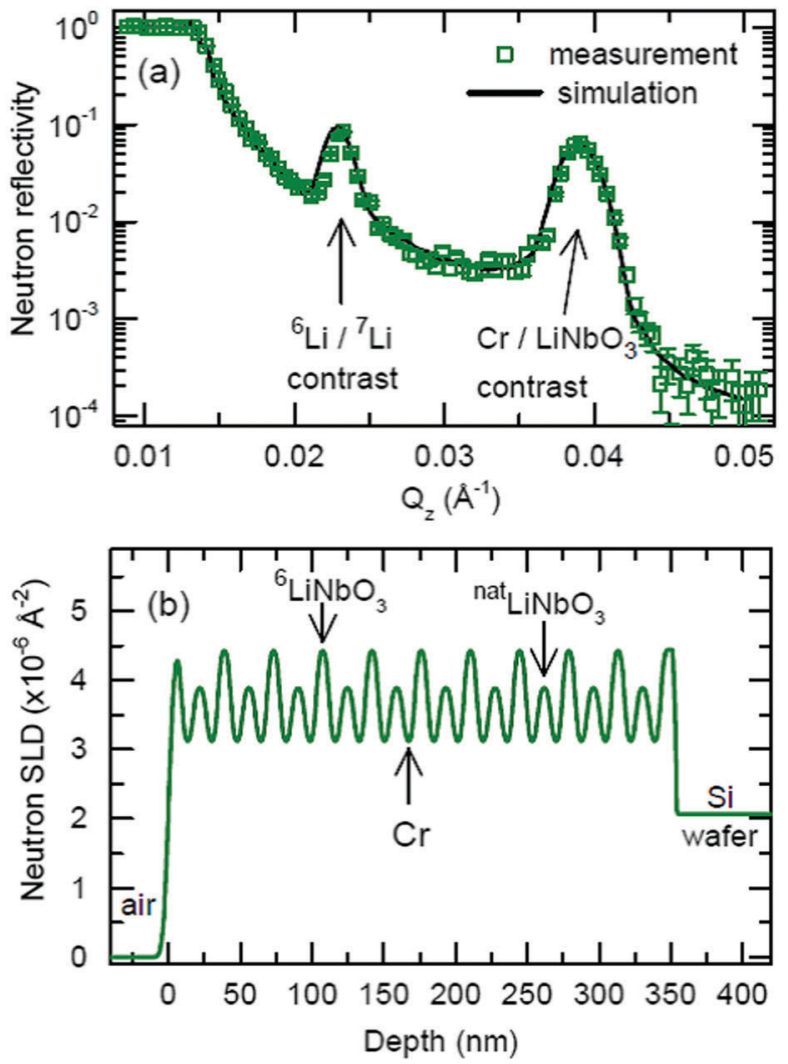

Fig. 5 (a) Measured NR pattern (open symbols) and corresponding Parratt32 simulations (line) for the superlattice with $\mathrm{Cr}$ spacer layers in the as-deposited state. (b) Neutron scattering length density obtained from the NR fit given in panel (a). Fitting parameters are given in Table 1.

for a double peak structure in the depth profile (Fig. 5b) thanks to the non-destructive nature of the neutrons. More information on this issue is given in ESI. $\dagger$

The samples were annealed in order to measure Li permeation within the scheduled neutron beam time. Fig. 6 presents the NR patterns measured from the superlattice with $\mathrm{Cr}$ spacer layers after sequential annealing at $100{ }^{\circ} \mathrm{C}(373 \mathrm{~K})$, together with NR simulation. The total reflection edge (located at $Q_{\mathrm{z}}=0.013 \AA^{-1}$ ) and the Bragg peak due to chemical contrast $\left(Q_{\mathrm{z}}=0.039 \AA^{-1}\right)$ do not change at all by annealing at $100{ }^{\circ} \mathrm{C}$ (see Fig. 6b). Solely, the Bragg peak due to $\mathrm{Li}$ isotope contrast diminishes which is confirmed also by the SIMS data (see Fig. 7b). Li permeation through $\mathrm{Cr}$ spacer layers takes place without any other (measurable) changes in the superlattice.

The fits to the measured NR patterns delivered the amount of $\mathrm{Li}$ isotope fractions in $\mathrm{Li}$ reservoirs. Fig. 8 shows how the $\mathrm{Li}$ isotope fraction in $\mathrm{Li}$ reservoirs changes with annealing time. The kinetics of Li isotope intermixing enables the determination of Li permeability. A fit of eqn (2) to the measured Li kinetic data of Fig. 8 determined the time constant of $\mathrm{Li}$ permeation to be $\tau=(4.6 \pm 0.5)$ hours. The Li permeability can be determined from eqn (4) to be $P=(2 \pm 0.5) \times 10^{-22} \mathrm{~m}^{2} \mathrm{~s}^{-1}$. The same procedure can be applied to the behaviour of ${ }^{7} \mathrm{Li}$ atoms, which results in the same permeability within error limits. 
Table 1 Parameters used for the simulation of the reflectivity pattern presented in Fig. 5, based on the Parratt32 code. The superlattice consists of ten $\left[{ }^{6} \mathrm{LiNbO}_{3} / \mathrm{Cr}^{\text {nat }}{ }^{\mathrm{LiNbO}} \mathrm{Li}_{3} / \mathrm{Cr}\right.$ ] four layer units (see Fig. 1b). The layers termed ${ }^{\text {nat }} \mathrm{LiNbO}_{3}$ and ${ }^{6} \mathrm{LiNbO}_{3}$ have a ${ }^{6} \mathrm{Li}$ and ${ }^{7} \mathrm{Li}$ isotope concentration of ${ }^{7} \mathrm{Li} 0.84^{6} \mathrm{Li}_{0.16}$ and ${ }^{7} \mathrm{Li}_{0.10^{6}} \mathrm{Li}_{0.90}$, respectively, as measured by SIMS (Fig. 3c). Error limits correspond to a $10 \%$ increase of $\chi^{2}$ of the best fit with respect to the fitted parameter only ${ }^{70}$

\begin{tabular}{|c|c|c|c|c|c|}
\hline & Layer & $\operatorname{SLD}\left(10^{-6} \AA^{-2}\right)$ & Thickness (nm) & Roughness (nm) & Mass-density $\left(\mathrm{g} \mathrm{cm}^{-3}\right)$ \\
\hline Capping-layer & ${ }^{6} \mathrm{LiNbO}_{3}$ & $4.45 \pm 0.2$ & $9.0 \pm 0.8$ & $3.0 \pm 1.0$ & $4.17 \pm 0.2$ \\
\hline Multilayer $\times 10$ & $\mathrm{Cr}$ & $3.1 \pm 0.1$ & $8.2 \pm 0.1$ & $1.8 \pm 0.5$ & $7.3 \pm 0.3$ \\
\hline & $\mathrm{Cr}$ & $3.1 \pm 0.1$ & $8.2 \pm 0.1$ & $1.8 \pm 0.5$ & $7.3 \pm 0.3$ \\
\hline & ${ }^{6} \mathrm{LiNbO}_{3}$ & $4.45 \pm 0.05$ & $8.9 \pm 0.1$ & $1.8 \pm 0.5$ & $4.17 \pm 0.1$ \\
\hline Si-wafer & $\mathrm{Si}$ & 2.07 & - & 0.5 & 2.3 \\
\hline
\end{tabular}
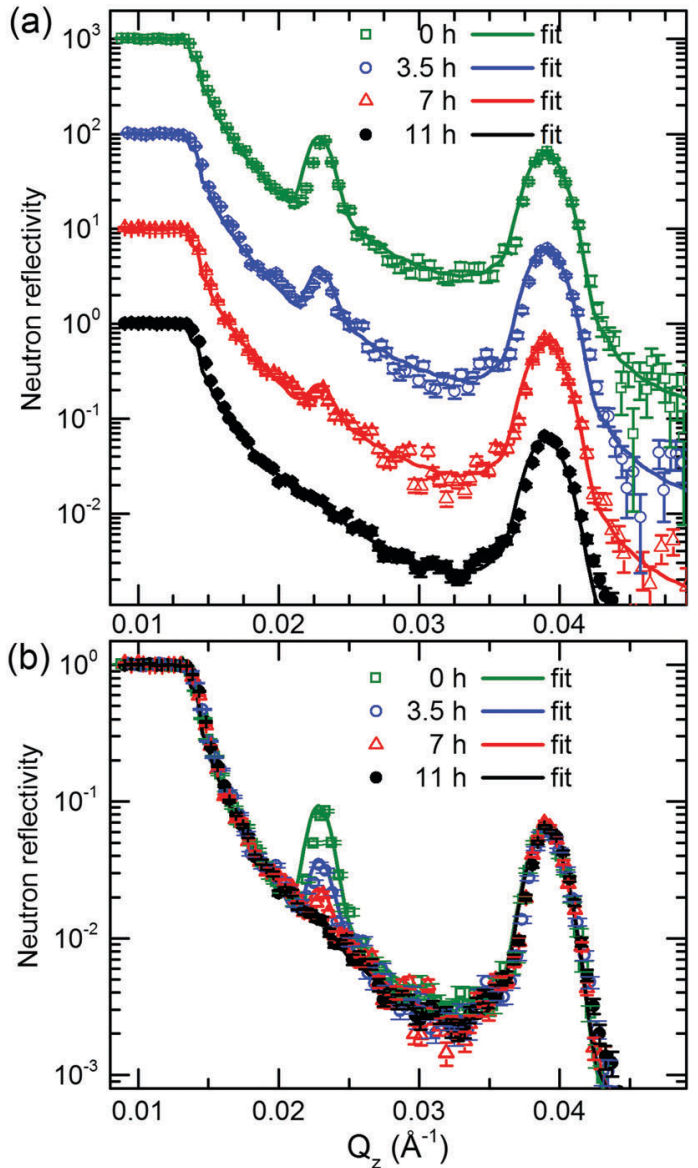

Fig. 6 Measured NR patterns (symbols) of the superlattice with $\mathrm{Cr}$ spacer layers in the as-deposited state and after annealing at $100{ }^{\circ} \mathrm{C}(373 \mathrm{~K})$ for $3.5 \mathrm{~h}, 7 \mathrm{~h}$, and $11 \mathrm{~h}$. The lines represent the Parratt32 fits to the measured patterns. (a) Reflectivity curves shifted in intensity for a better visualization of the Bragg peak decrease. (b) Non-shifted reflectivity curves for a proper visualization of the lack of changes in the total reflection edge and in the Bragg peak due to chemical contrast.

The Li diffusion coefficient in amorphous $\mathrm{LiNbO}_{3}$ films annealed at $100{ }^{\circ} \mathrm{C}(373 \mathrm{~K})$ was measured by Rahn et al. ${ }^{57}$ to be $D=2.6 \times$ $10^{-16} \mathrm{~m}^{2} \mathrm{~s}^{-1}$. Considering the Li solubility in $\mathrm{LiNbO}_{3}$ to amount to 0.2 , a Li permeability of $P=5.2 \times 10^{-17} \mathrm{~m}^{2} \mathrm{~s}^{-1}$ is obtained for the $\mathrm{Li}$ flux through the $\mathrm{LiNbO}_{3}$ reservoir layers at $100{ }^{\circ} \mathrm{C}(373 \mathrm{~K})$. This value is $\mathbf{5}$ orders of magnitude higher than that measured here in the superlattice at $100{ }^{\circ} \mathrm{C}\left(P=(2 \pm 0.5) \times 10^{-22} \mathrm{~m}^{2} \mathrm{~s}^{-1}\right)$.

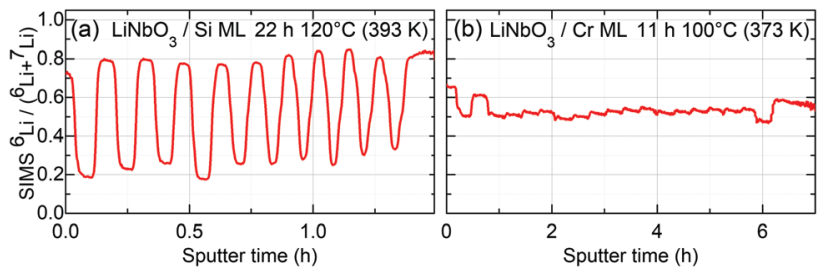

Fig. $7{ }^{6} \mathrm{Li}$ fraction measured by SIMS from (a) the ML with Si spacer layers after $22 \mathrm{~h}$ of annealing at $120{ }^{\circ} \mathrm{C}(393 \mathrm{~K})$ and (b) the $\mathrm{ML}$ with $\mathrm{Cr}$ spacer layers after $11 \mathrm{~h}$ of annealing at $100{ }^{\circ} \mathrm{C}(373 \mathrm{~K})$.

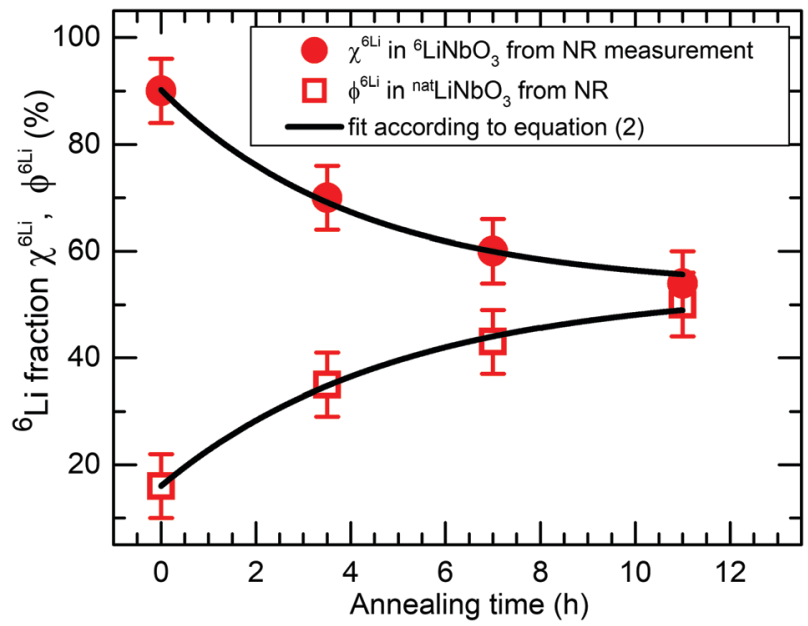

Fig. 8 Relative ${ }^{6} \mathrm{Li}(\mathrm{a})$ and ${ }^{7} \mathrm{Li}$ (b) fractions of the ${ }^{6} \mathrm{LiNbO}_{3}$ and ${ }^{\text {nat }} \mathrm{LiNbO}_{3}$ layers of the superlattice with $\mathrm{Cr}$ spacer layers, respectively, as a function of annealing time as obtained from the Parratt32 fits to measured NR patterns (Fig. 6). The lines represent the fit of eqn (2) to measured data.

Hence, also at $100{ }^{\circ} \mathrm{C}$, the $\mathrm{Li}$ flux in the superlattice is controlled by the Li blocking effect of the Cr spacer layers, i.e. by the Li permeation through Cr layers.

Fig. 9 presents the Li permeation experiments through $9 \mathrm{~nm}$ thin Si spacer layers as traced by NR. The experiments revealed that Li permeation through the Si layers is much slower than through the Cr spacer layers. Even a higher annealing temperature $\left(120{ }^{\circ} \mathrm{C}(393 \mathrm{~K})\right)$ over a longer annealing time $(22 \mathrm{~h})$ does not diminish any NR Bragg peaks, i.e. not even that induced by the Li isotope contrast. This is in agreement with the SIMS depth profiling (see Fig. 7). These experiments show that Si layers are 


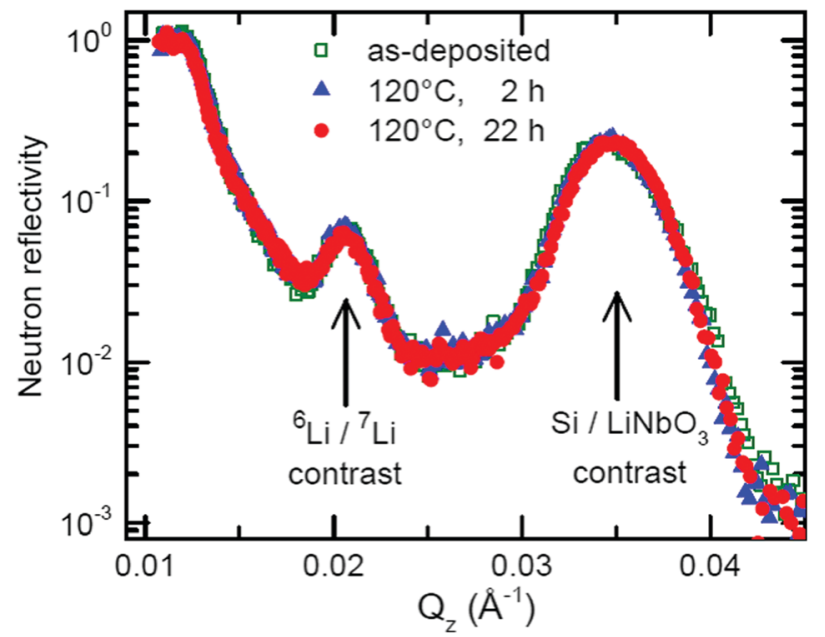

Fig. 9 NR patterns measured from the multilayer with Si spacer layers after several annealing steps performed at $120{ }^{\circ} \mathrm{C}$.

less permeable to $\mathrm{Li}$ than $\mathrm{Cr}$ layers. The aforementioned experiments at room temperature have shown that Li permeation through $\mathrm{C}$ layers is faster than through $\mathrm{Cr}$ layers. Hence, $\mathrm{Li}$ permeation through $\mathrm{Cr}$ layers is faster than through Si layers but slower than through $\mathrm{C}$ layers. In turn this evidences that (also above room temperature) Li permeation is not controlled by $\mathrm{Li}$ diffusion in $\mathrm{LiNbO}_{3}$ layers.

A possible explanation for the higher Li permeation through the $\mathrm{Cr}$ layers in comparison to the Si layers could be different impurity (e.g. oxygen) contents and different crystallographic structures of the Si and Cr layers. It can be expected that the proximity of ultrathin spacer layers to oxide based Li reservoirs oxidizes the spacer layers. In that case, the Li permeation experiments were performed through silicon oxide and chromium oxide $^{78}$ layers and not through elemental Si and Cr layers. One has to know the material constitution through which Li permeation was measured.

Before doing so, let us mention that the presented methodology can be applied to measure the (diffusion or interface controlled) rate determining step of the $\mathrm{Li}$ transport process in nanometer sized layers. Li permeation induces a mutual inter-diffusion of the two different $\mathrm{Li}$ isotopes across the interface between the spacer layer (e.g. $\mathrm{Cr}$, Si or $\mathrm{C}$ ) and the solid state reservoir layer. An interface controlled lithium transport process is evidenced if the transport process lacks a dependence of the lithium isotope exchange rate on the spacer layer thickness. Nonetheless, a diffusion controlled process is expected to show considerable dependence on the spacer layer thickness. ${ }^{2}$

\subsection{Extended characterisation of spacer layers}

Investigations by cross sectional TEM would provide direct information on the chemical composition, layer crystallinity, interface roughness and waviness, grain size, boundary and composition. If nothing else, at least this work provides a full characterization of the as-deposited and annealed MLs with a plethora of non-destructive measurement techniques like NR, GI-XRD, FTIR, Raman scattering, X-ray absorption spectroscopy and magnetic measurements. The results are presented in detail in the ESI accompanying this work ${ }^{2}$ and they are briefly summarized here.

Raman scattering found the carbon spacer layers to be amorphous with low $\mathrm{sp}^{3}$ content, as expected for ion beam sputter-deposited carbon coatings. GI-XRD reveals that the $\mathrm{LiNbO}_{3}, \mathrm{Si}$ and $\mathrm{C}$ spacer layers are amorphous whereas the $\mathrm{Cr}$ spacer layers are polycrystalline with elemental bcc chromium. There is no evidence of crystalline Cr-oxide. Chromium oxide was also not detected by FTIR and also not by Raman scattering. The neutron SLDs obtained from NR can be explained only with elemental chromium. EXAFS was performed in situ during Li permeation by heating the superlattice to $100{ }^{\circ} \mathrm{C}(373 \mathrm{~K})$ in air.

The EXAFS experiments revealed the $\mathrm{Cr}$ bonding environment to be 80 percent of $\mathrm{Cr}$ metal and 20 percent of Cr-oxide with no further evidence of oxidation during the superlattice heating (see Fig. 10). We emphasize that this is not a crystalline phase ratio, but the distinction is based on the atomic neighbourhood derived from XAFS measurements. However, the EXAFS study cannot discern if the measured chromium oxide stems from the $\mathrm{Cr}$ layers or from the $\mathrm{Cr}$ atoms located inside the $\mathrm{LiNbO}_{3}$ layers. Overall, these experiments evidenced that the ultrathin Cr layers are not (fully) oxidized. The crystallographic network (polycrystalline for Cr layers and amorphous for $\mathrm{Si}$, $\mathrm{C}$ and $\mathrm{LiNbO}_{3}$ layers) and the chemistry of the multilayers do not change significantly by the performed Li permeation (i.e. annealing) experiments. GI-XRD experiments measured a high stress of $12 \mathrm{GPa}$ acting on the bcc Cr grains (in the Cr spacer layers of the superlattice) which does not change with the performed $\mathrm{Li}$ permeation experiments. Li permeation was measured in an, otherwise, conserved multilayer network.

However, one may note that the large stress of $12 \mathrm{GPa}$ measured in the $\mathrm{Cr}$ spacer layer can be a symptom that the piezoelectric material of the $\mathrm{LiNbO}_{3}$ layers is under strain. The strain can induce a piezoelectric electric field over the (e.g. Cr)

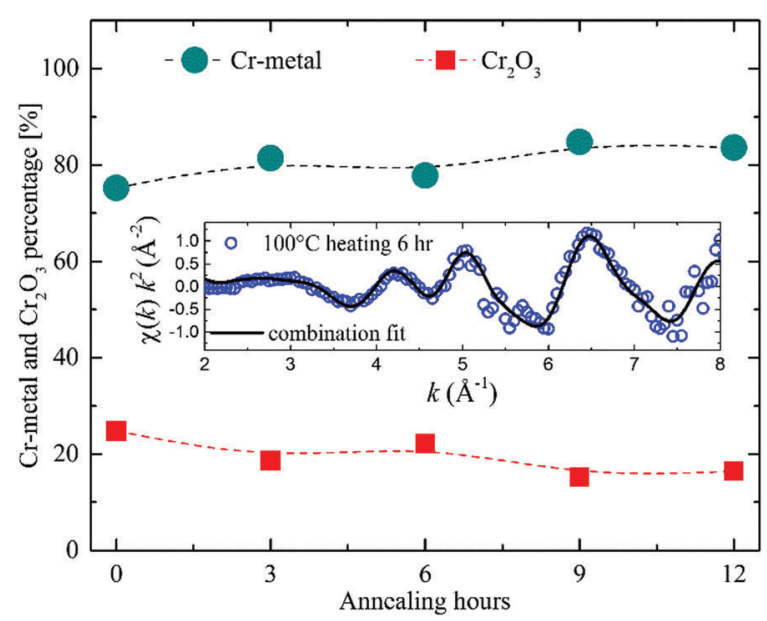

Fig. 10 Percentage of $\mathrm{Cr}$-metal and $\mathrm{Cr}_{2} \mathrm{O}_{3}$ existent in $\mathrm{LiNbO}_{3}$ superlattices with $\mathrm{Cr}$ spacer layers as obtained from in situ EXAFS measurements during annealing in air at $100{ }^{\circ} \mathrm{C}(373 \mathrm{~K}) .^{2}$ The inset graph shows in situ measured EXAFS data (circles) with the corresponding combination fit data (line). 
spacer layer which can promote or suppress the $\mathrm{Li}$ ion transport. ${ }^{81,82}$ This is of importance for self-charging LIBs that hybridize mechanical energy harvesting and ion storage processes into one process. ${ }^{81,82}$

Fig. 11 presents the measured magnetic $m(H)$ characteristics at room temperature of the multilayers with $\mathrm{Cr}, \mathrm{Si}$ and $\mathrm{C}$ spacer layers. They show a clear diamagnetic response due to (at least) the diamagnetic Si wafer substrate (see panels a, c, e of Fig. 11). The diamagnetic contribution is overlapped by a magnetic hysteresis for the multilayers with $\mathrm{Cr}$ and $\mathrm{Si}$ spacer layers (e.g. Fig. 11b and $\mathrm{d}$, respectively). Small magnetic moments can be caused by traces of magnetic impurities (Fe, Co and/or $\mathrm{Ni}$ ) introduced into the sample during the sample handling or multilayer deposition. ${ }^{71,72}$ For example, a small amount of Fe, Co or $\mathrm{Ni}$ is perhaps incorporated in the multilayer during $\mathrm{ML}$ deposition from the IBS sputter chamber walls and/or from the target holder and sample holder. In that case, it should have been expected that the ML with carbon spacer layers should also show a ferromagnetic contribution in the SQUID measurement. The latter is not the case (see Fig. 11e and f) here. Hence, a ferromagnetic spin alignment, caused by $\mathrm{Cr}$ and Si elements in the multilayers with $\mathrm{Cr}$ and Si spacer layers, cannot be ruled out.

Earlier, unexpected ferromagnetism at room temperature was measured in $\mathrm{Cr}^{72-76}$ and $\mathrm{Si}^{77}$ doped thin films of nonferromagnetic nitrides and oxides. The observed ferromagnetism can be correlated to structural defects induced by the doping species (i.e. $\mathrm{Cr}$ and $\mathrm{Si}$ ). Similarly, the measured magnetic hysteresis in Fig. 11b and d could stem from the presence of
$\mathrm{Cr}$ and $\mathrm{Si}$ inside the $\mathrm{LiNbO}_{3}$ layers. Interface related ferromagnetism can appear by a charge transfer mechanism. ${ }^{72,79}$ This means that the space charge layers in between $\mathrm{LiNbO}_{3}$ and $\mathrm{Cr}$ (and $\mathrm{Si}$ ) can induce ferromagnetic order in the layers. One may note that, due to the ultrathin fashion of the layers, the space charge layer can extend throughout the entire ultrathin layers. ${ }^{22,23}$ An electric field over the spacer layer can appear also due to the piezoelectric property of the $\mathrm{LiNbO}_{3}$ layers. The large stress of $12 \mathrm{GPa}$ measured by X-ray scattering (GIXRD) in the Cr spacer layers may be evidence that the piezoelectric material of the $\mathrm{LiNbO}_{3}$ layers is under strain. The strain can induce a piezoelectric electric field over the (e.g. Cr) spacer layer, ${ }^{81,82}$ which can affect the electronic structure of the spacer layer. Further discussion on magnetic behaviour is given in the related ESI. ${ }^{2}$

The class of multilayers presented in this work opens up the possibility to investigate the influence of (i) layer chemistry and layer thicknesses, (ii) additional mechanical stress imposed on the multilayers by using sample bending devices, and (iii) the annealing temperature and annealing time interval, on multilayer properties such as magnetism and on the ability to measure Li permeation.

Before concluding let us discuss if the measured spacer layer characteristics might help to explain the measured $\mathrm{Li}$ permeation strength. Li permeation through carbon layers was found to be faster than through chromium layers and the latter to be faster than through silicon layers. The difference in $\mathrm{Li}$ permeability might occur due to different diffusivities $(D)$. According to eqn (5) $(P=S D)$, the Li permeability $(P)$ also
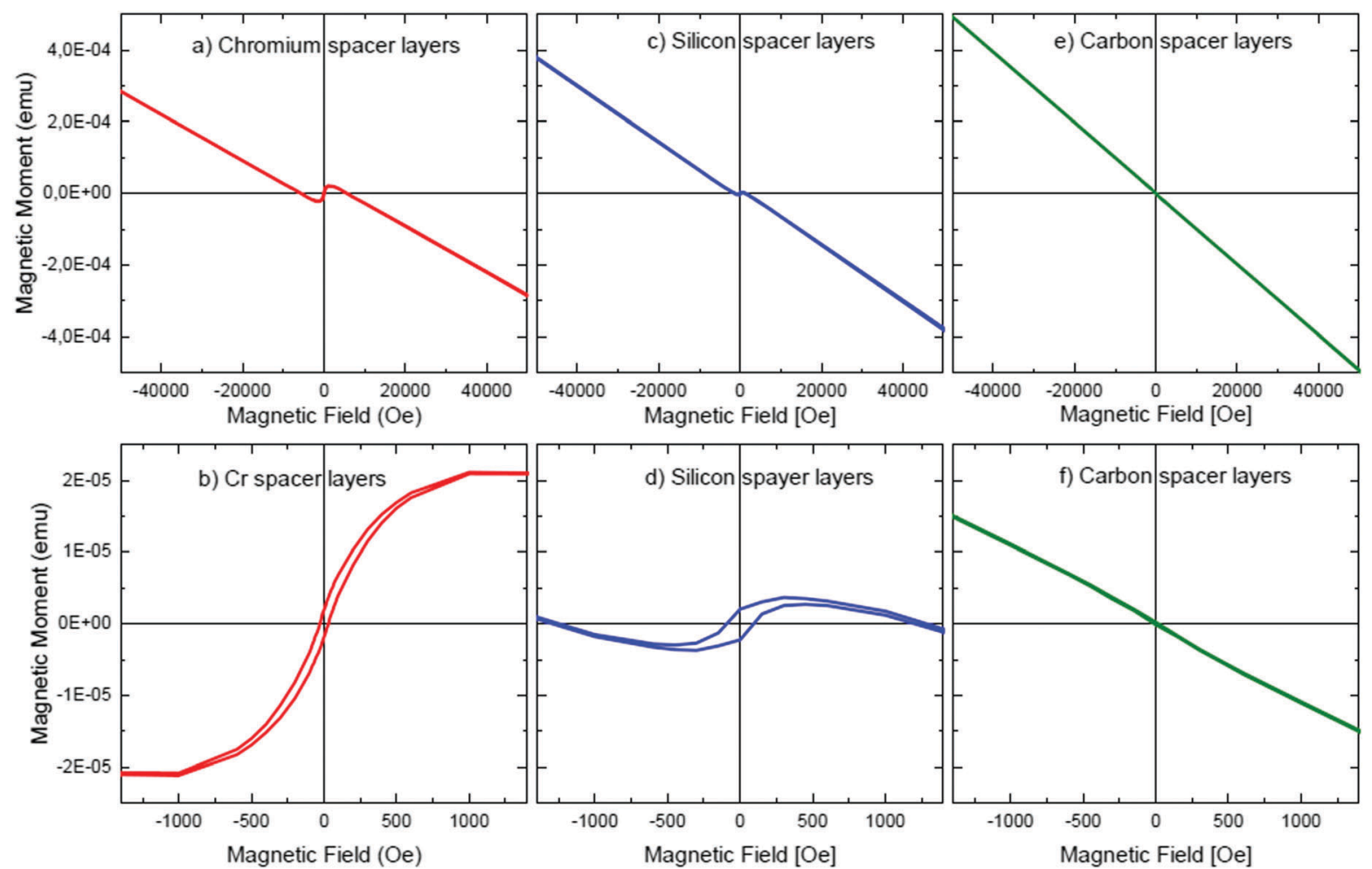

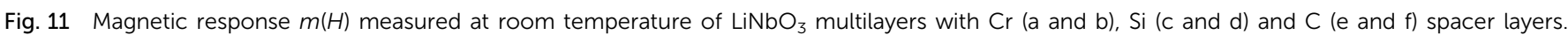
(b, $d$ and f) Magnetic characteristics on an enlarged scale for better visualisation of magnetic hysteresis. 
increases if the Li solubility $(S)$ increases for a constant diffusivity. Chromium layers were found to be polycrystalline, whereas the silicon layers were found to be amorphous. The structure of the carbon layers was found to be amorphous with a predominantly graphitic like ( $\mathrm{sp}^{2}$ hybridization) configuration and in that manner to be low density carbon. Carbon atoms in a graphitic structure are arranged in parallel densely packed hexagonal atomic layers. There is no chemical bonding between the hexagonal layers and Li can be inserted rather easily between the layers. Consequently, the $\mathrm{Li}$ diffusivity and solubility is high in graphitic like carbon. The lithium solubility is well above $10^{-2} \mathrm{Li}$ per $\mathrm{C}$ atom. ${ }^{87,88}$ This might explain the measured higher $\mathrm{Li}$ permeation through carbon spacer layers. In contrast, the Li diffusivity and solubility in amorphous silicon is extremely low. ${ }^{80}$ The lithium solubility in amorphous silicon should be in the range of $10^{-9} \mathrm{Li}$ per $\mathrm{Si}$ atom, ${ }^{80}$ and, consequently, more than seven orders of magnitude lower than in carbon. In the case of chromium, as mentioned in Section 3.2, Li does not alloy with it. $^{68,69}$ In similarity to $\mathrm{Si}$, one can expect that the solubility of $\mathrm{Li}$ in $\mathrm{Cr}$ is also very low. For the comparison of Li permeation through $\mathrm{Cr}$ and $\mathrm{Si}$ layers, it is reasonable to assume that Li can diffuse fast along the grain boundaries of the polycrystalline structure of the Cr spacer layers. The grain boundaries might also accommodate a higher amount of Li (increased Li solubility) than the bulk of grains. This is not the case for amorphous silicon. Amorphous Si has no grain boundaries but a continuous covalent network which may serve as an effective barrier for Li permeation. ${ }^{80}$

\section{Conclusions}

New layered materials were fabricated by ion beam sputtering deposition of a superlattice with twenty-one thin lithium niobate layers $(9 \mathrm{~nm})$ spaced by thin $(8 \mathrm{~nm}) \mathrm{Cr}$, Si and C spacer layers. The multilayers were primarily used to measure Li permeation through the respective ultrathin $\mathrm{Cr}$, Si and $\mathrm{C}$ spacer layers. The $\mathrm{LiNbO}_{3}$ layers serve as $\mathrm{Li}$ reservoirs. Each second $\mathrm{LiNbO}_{3}$ layer was enriched with ${ }^{6} \mathrm{Li}$ or ${ }^{7} \mathrm{Li}$ isotopes. The superlattice therefore possesses a $\mathrm{Li}$ isotope contrast and a $\mathrm{LiNbO}_{3} /$ spacer layer $(\mathrm{Cr}$, $\mathrm{Si}$ or $\mathrm{C}$ ) material contrast. The Li isotope fraction in the multilayer was measured with secondary ion mass spectrometry and neutron reflectometry. Li permeation through the spacer layers changes the Li isotope contrast within the Li reservoirs. This enables us to determine the Li permeability from the time constant of Li isotope contrast change. The measurements were performed without applying an electrical driving force.

At room temperature, Li permeation was found to be extremely slow. On the one hand, Li permeation in the ML with $\mathrm{C}$ spacer layers diminishes the Li isotope contrast after 5 years of ML storage in air at room temperature. On the other hand, the $\mathrm{Li}$ isotope contrast in the MLs with $\mathrm{Cr}$ and Si spacer layers is only marginally decreased after 5 years of storage in air at room temperature. From these experiments, a full intermixing of the $\mathrm{Li}$ isotopes is expected in some one hundred years for $\mathrm{Cr}$ and $\mathrm{Si}$ layers at room temperature. $\mathrm{The} \mathrm{Cr}$ and Si spacer layers are expected to effectively block the Li flux.

Accelerated Li permeation was achieved by annealing treatments. Li permeation through Cr layers at $100{ }^{\circ} \mathrm{C}(373 \mathrm{~K})$ was measured non-destructively by neutron reflectometry. A full intermixing of the Li isotopes is seen after 11 hours of annealing at $100{ }^{\circ} \mathrm{C}(373 \mathrm{~K})$. A Li permeability of $P=(2 \pm 0.5) \times 10^{-22} \mathrm{~m}^{2} \mathrm{~s}^{-1}$ was determined from the measured time-constant for Li permeation of $\tau=(4.6 \pm 0.5)$ hours. The Li permeability value is five orders of magnitude lower than the value of the Li flux through $\mathrm{LiNbO}_{3}$ layers, evidencing that the measured Li permeability stems from the Li permeation through the $\mathrm{Cr}$ spacer layers. Overall, Li permeation through $\mathrm{C}$ layers was found to be faster than through Cr layers and the latter to be faster than through Si layers. Additional Li permeation experiments are planned to substantiate this statement more quantitatively.

Additional experiments using multiple non-destructive measurement techniques revealed that $\mathrm{Li}$ permeation was measured in an, otherwise, conserved multilayer network. The Si and C spacer layers were found to be amorphous, while the $\mathrm{Cr}$ spacer layer was found to be polycrystalline with bcc $\mathrm{Cr}$ grains. The $\mathrm{C}$ spacer layers possess a predominant graphitic like $\left(\mathrm{sp}^{2}\right)$ bonding configuration. These multilayer characteristics might help to explain the difference of $\mathrm{Li}$ permeation found in the spacer layers. Furthermore, the superlattice with $\mathrm{Cr}$ spacer layers exercises a high stress of $12 \mathrm{GPa}$ on $\mathrm{Cr}$ grains which does not change by Li permeation (i.e. after annealing). Eighty percent of the $\mathrm{Cr}$ atoms have a metallic $\mathrm{Cr}$ and 20 percent a chromium oxide bonding environment (situated at interfaces). Lastly, a weak ferromagnetic signal at room temperature was measured for the multilayers with $\mathrm{Cr}$ and $\mathrm{Si}$ spacer layers but not for the multilayers with $\mathrm{C}$ spacer layers.

\section{Conflicts of interest}

There are no conflicts to declare.

\section{Acknowledgements}

Financial support from the Deutsche Forschungsgemeinschaft (DFG) under the contract HU 2170/2-1 is gratefully acknowledged. This research project has been supported by the European Commission under the 7th Framework Programme through the 'Research Infrastructures' action of the 'Capacities' Programme, NMI3-II grant number 283883. This work is based on experiments performed at the Swiss spallation neutron source (SINQ), at the instruments AMOR and Morpheus, PSI Villigen, Switzerland. Thanks are due to H. Schmidt (TU-Clausthal) for the development of the model for Li permeability extraction from measured data, E. Witt and P. Heitjans (U Hannover) for preparing the $\mathrm{LiNbO}_{3}$ sputter targets, K. Bode (TU-Clausthal) for the Raman measurement and M. Opel (TU München) for the SQUID measurements.

\section{Notes and references}

1 The work shows that $\mathrm{LiNbO}_{3}$ multilayers with $\mathrm{Cr}$ spacer layers possess crystalline (polycrystalline) Cr layers whereas all layers of the multilayers with alternating $\operatorname{Si}(\mathrm{C})$ and $\mathrm{LiNbO}_{3}$ material are amorphous. Hence, throughout this work the terminology of superlattice will be used only for 
multilayers of alternating $\mathrm{Cr}$ and $\mathrm{LiNbO}_{3}$ layers and not for the multilayers of alternating $\mathrm{Si}(\mathrm{C})$ and $\mathrm{LiNbO}_{3}$ layers. ${ }^{2}$.

2 Further information is presented in the ESI $\dagger$ accompanying this work. It contains a literature survey, details on multilayer preparation and analysis of microscopy, SIMS, NR, GIXRD, FTIR, Raman scattering and XAS data, and a discussion on magnetic behavior.

3 A. K. Yadav, C. T. Nelson, S. L. Hsu, Z. Hong, J. D. Clarkson, C. M. Schlepütz, A. R. Damodaran, P. Shafer, E. Arenholz, L. R. Dedon, D. Chen, A. Vishwanath, A. M. Minor, L. Q. Chen, J. F. Scott, L. W. Martin and R. Ramesh, Nature, 2016, 530, 198.

4 D. Puggioni, G. Giovannetti, M. Capone and J. M. Rondinelli, Phys. Rev. Lett., 2015, 115, 087202.

5 A. Paul, Sci. Rep., 2016, 6, 19315, DOI: 10.1038/srep19315.

6 Z. Wang, L. P. H. Jeurgens, W. Sigle and E. J. Mittemeijer, Phys. Rev. Lett., 2015, 115, 016102.

7 S. Ghosh, S. Tongay, A. F. Hebard, H. Sahin and F. M. Peeters, J. Magn. Magn. Mater., 2014, 349, 128.

8 A. Ohtomo, D. A. Muller, J. L. Grazul and H. Y. Hwang, Nature, 2002, 419, 378.

9 J. S. White, M. Bator, Y. Hu, H. Luetkens, J. Stahn, S. Capelli, S. Das, M. Döbeli, Th. Lippert, V. K. Malik, J. Martynczuk, A. Wokaun, M. Kenzelmann, Ch. Niedermayer and C. W. Schneider, Phys. Rev. Lett., 2013, 111, 037201.

10 F. A. Ma'Mari, T. Moorsom, G. Teobaldi, W. Deacon, Th. Prokscha, H. Luetkens, S. Lee, G. E. Sterbinsky, D. A. Arena, D. A. MacLaren, M. Flokstra, M. Ali, M. C. Wheeler, G. Burnell, B. J. Hickey and O. Cespedes, Nature, 2015, 524, 69.

11 U. Bauer, L. Yao, S. Emori, H. L. Tuller, S. van Dijken and G. S. D. Beach, Nat. Mater., 2015, 14, 174.

12 C.-C. Chen, L. Fu and J. Maier, Nature, 2016, 536, 159.

13 A. Paul, E. Kentzinger, U. Rücker, D. E. Bürgler and P. Grünberg, Phys. Rev. B: Condens. Matter Mater. Phys, 2004, 70, 224410.

14 R. T. Tung, Appl. Phys. Rev., 2014, 1, 011304.

15 J. Maier, J. Electroceram., 2015, 34, 69.

16 N. Kamaya, K. Homma, Y. Yamakawa, M. Hirayama, R. Kanno, M. Yonemura, T. Kamiyama, Y. Kato, S. Hama, K. Kawamoto and A. Mitsui, Nat. Mater., 2011, 10, 682.

17 M. Ogawa, R. Kanda, K. Yoshida, T. Uemura and K. Harada, J. Power Sources, 2012, 205, 487.

18 N. Ohta, K. Takada, I. Sakaguchi, L. Zhang, R. Ma, K. Fukuda, M. Osada and T. Sasaki, Electrochem. Commun., 2007, 9, 1486.

19 K. Takada, N. Ohta, L. Zhang, K. Fukuda, I. Sakaguchi, R. Ma, M. Osada and T. Sasaki, Solid State Ionics, 2008, 179, 1333.

20 H. Yamada, Y. Oga and I. Moriguchi, J. Electrochem. Soc., 2012, 159, A380.

21 D. Ruzmetov, et al., Nano Lett., 2012, 12, 505.

22 J. Maier, Nat. Mater., 2005, 4, 805.

23 L. A. Haverkate, W. K. Chan and F. M. Mulder, Adv. Funct. Mater., 2010, 20, 4107.

24 C. Li, L. Gu, X. Guo, D. Samuelis, K. Tang and J. Maier, Nano Lett., 2012, 12, 1241.
25 K. Takada, N. Ohta and Y. Tateyama, J. Inorg. Organomet. Polym., 2015, 25, 205.

26 F. Zhao and A. V. Virkar, J. Power Sources, 2010, 195, 6268.

27 L. Fu, C.-C. Chen, D. Samuelis and J. Maier, Phys. Rev. Lett., 2014, 112, 208301.

28 J. Maibach, F. Lindgren, H. Eriksson, K. Edström and M. Hahlin, J. Phys. Chem. Lett., 2016, 7, 1775.

29 R. Yu, S. Niu, C. Pan and Z. L. Wang, Nano Energy, 2015, 14, 312.

30 S. Kim, J. Fleig and J. Maier, Phys. Chem. Chem. Phys., 2003, 5, 2268.

31 X. Guo, W. Sigle, J. Fleig and J. Maier, Solid State Ionics, 2002, 154-155, 555.

32 A. A. Felix, J. L. M. Rupp, J. A. Varela and M. O. Orlandi, J. Appl. Phys., 2012, 112, 054512.

33 S. Schweiger, M. Kubicek, F. Messerschmitt, Ch. Murer and J. L. M. Rupp, ACS Nano, 2014, 8, 5032.

34 M. Dawber, K. M. Rabe and J. F. Scott, Rev. Mod. Phys., 2005, 77, 1083.

35 V. Ievlev, M. Sumets, A. Kostyuchenko, O. Ovhcinnikov, V. Vakhtel and S. Kannykin, Thin Solid Films, 2013, 542, 289.

36 C. Leroux, S. Baudot, M. Charbonnier, A. Van Der Geest, P. Caubet, A. Toffoli, Ph. Blaise, G. Ghibaude, F. Martin and G. Reimbold, Solid-State Electron., 2013, 88, 21.

37 E. Hüger and K. Osuch, Eur. Phys. J. B, 2004, 37, 149.

38 E. Hüger and K. Osuch, Europhys. Lett., 2003, 63, 90.

39 E. Hüger and K. Osuch, Solid State Commun., 2004, 131, 175.

40 E. Hüger and K. Osuch, Eur. Phys. J. B, 2004, 44, 145.

41 E. Hüger and K. Osuch, Phys. Rev. B: Condens. Matter Mater. Phys., 2005, 72, 085432.

42 T. Kana, E. Hüger, D. Legut, M. Cak and M. Sob, Phys. Rev. B, 2016, 93, 134422.

43 A. R. Jimenez, R. Klöpsch, R. Wagner, U. Rodehorst, M. Kolek, R. Nölle, M. Winter and T. Placke, ACS Nano, 2017, 11, 4731.

44 D. H. Snydacker, M. Aykol, S. Kirklin and C. Wolverton, J. Electrochem. Soc., 2016, 163, A2054.

45 T. T. Fister, J. Esbenshade, X. Chen, B. R. Long, B. Shi, Ch. M. Schlepütz, A. G. Gewirth, M. J. Bedzyk and P. Fenter, Adv. Energy Mater., 2014, 4, 1301494.

46 J. K. Lee, B. K. Kim and W. Y. Yoon, Solid State Ionics, 2014, 249-250, 117.

47 S. W. Hwang, J. K. Lee and W. Y. Yoon, J. Power Sources, 2013, 244, 620.

48 J. H. Lee, J. K. Lee and W. Y. Yoon, ACS Appl. Mater. Interfaces, 2013, 5, 7058.

49 M. T. McDowell, S. W. Lee, W. D. Nix and Y. Cui, Adv. Mater., 2013, 25, 4966.

50 L. Y. Beaulieu, K. W. Eberman, R. L. Turner, L. J. Krause and J. R. Dahn, Electrochem. Solid-State Lett., 2001, 4, A137.

51 S. D. Jones and J. R. Akridge, J. Power Sources, 1993, 44, 505. 52 A. Brazier, L. Dupont, L. Dantras-Laffont, N. Kuwata, J. Ka-wamura and J.-M. Tarascon, Chem. Mater., 2008, 20, 2352.

53 C. Yu, X. Li, T. Ma, J. Rong, R. Zhang, J. Shaffer, Y. An, Q. Liu, B. Wei and H. Jiang, Adv. Energy Mater., 2012, 2, 68.

54 M. E. Holtz, Y. Yu, D. Gunceler, J. Gao, R. Sundararaman, K. A. Schwarz, T. A. Arias, H. D. Abruna and D. A. Muller, Nano Lett., 2014, 14, 1453. 
55 R. C. Munoz and C. Arenas, Appl. Phys. Rev., 2017, 4, 011102.

56 E. Hüger, L. Dörrer, J. Rahn, T. Panzner, J. Stahn, G. Lilienkamp and H. Schmidt, Nano Lett., 2013, 13, 1237.

57 J. Rahn, E. Hüger, L. Dörrer, B. Ruprecht, P. Heitjans and H. Schmidt, Z. Phys. Chem., 2012, 226, 439.

58 P. Wang, A. Kozlov, D. Thomas, F. Mertens and R. SchmidtFetzer, Intermetallics, 2013, 42, 137.

59 M. Zeilinger, I. M. Kurylyshyn, U. Häussermann and T. F. Fässler, Chem. Mater., 2013, 25, 4623.

60 A. J. Morris, C. P. Grey and Ch. J. Pickard, Phys. Rev. B: Condens. Matter Mater. Phys., 2014, 90, 054111.

61 M. H. Braga, A. Debski and W. Gasior, J. Alloys Compd., 2014, 616, 581.

62 S. Zhang, Y. Wang, G. Yang and Y. Ma, ACS Appl. Mater. Interfaces, 2016, 8, 16761.

63 H.-H. Chiang, J.-M. Lu and C.-L. Kuo, J. Chem. Phys., 2016, 144, 034502.

64 H. Reiss, C. S. Fuller and A. J. Pietruszkiewicz, J. Chem. Phys., 1956, 25, 650.

65 C. S. Fuller and H. Reiss, J. Chem. Phys., 1957, 27, 318.

66 E. M. Pell, J. Phys. Chem. Solids, 1957, 3, 77.

67 Impurities and Defects in Group IV Elements, IV-IV and IIIV Compounds, Part a: Group IV Elements, Silicon, solubility data of impurities: group IIA, in Landolt-Börnstein Series Group III Condensed Matter, Series 41A2a, ed. O. Madelung, U. Rössler and M. Schulz, Springer Berlin Heidelberg, 2002, DOI: 10.1007/10681604_38.

68 M. Venkatram and J. P. Neumann, Bull. Alloy Phase Diagrams, 1984, 5, 399.

69 Phase Equilibria, Crystallographic and Thermodynamic Data of Binary Alloys Cr-Cs - Cu-Zr, Cr-Li (Chromium-Lithium), in Landolt-Börnstein Series - Group IV Physical Chemistry, Series $5 d$, ed. B. Predel and O. Madelung, Springer Berlin Heidelberg, 1994, DOI: 10.1007/10086090_986.
70 B. Jerliu, L. Dörrer, E. Hüger, G. Borchardt, R. Steitz, U. Geckle, V. Oberst, M. Bruns, O. Schneider and H. Schmidt, Phys. Chem. Chem. Phys., 2013, 15, 7777.

71 E. Wistrela, A. Bittner, M. Schneider, M. Reissner and U. Schmid, J. Appl. Phys., 2017, 121, 115302.

72 G. R. Patzke, Y. Zhou, R. Kontic and F. Conrad, Angew. Chem., Int. Ed., 2011, 50, 826.

73 D. Kumar, J. Antifakos, M. G. Blamire and Z. H. Barber, Appl. Phys. Lett., 2004, 84, 5004.

74 H. X. Liu, S. Y. Wu, K. R. Singh, L. Gu, D. J. Smith, N. Newman, N. R. Dilley, L. Montes and M. B. Simmonds, Appl. Phys. Lett., 2004, 85, 4076.

75 F. Pan, C. Song, X. J. Liu, Y. C. Yang and F. Zeng, Mater. Sci. Eng., $R, 2008,62,1$.

76 R. Singh, J. Magn. Magn. Mater., 2013, 346, 58.

77 D. Pan, J. K. Jian, Y. F. Sun and R. Wu, J. Alloys Compd., 2012, 519, 41.

78 H. Y. Hwang and S.-W. Cheong, Science, 1997, 278, 1607.

79 M. A. Garcia, J. Zuniga-Perez, V. Munoz-Sanjose, J. Colchero and E. Palacios-Lidon, Nano Lett., 2007, 7, 1489.

80 E. Hüger, L. Dörrer and H. Schmidt, Chem. Mater., 2018, 30, 3254-3264, DOI: 10.1021/acs.chemmater.8b00186.

81 Z. Wang, Z. Li and Y. Q. Fu, ChemElectroChem, 2017, 4, 1523.

82 Z. Wang, ACS Appl. Mater. Interfaces, 2017, 9, 15893.

83 D. Rehnlund, J. Pettersson, K. Edström and L. Nyholm, ChemistrySelect, 2018, 3, 2311-2314.

84 D. Rehnlund, F. Lindgren, S. Böhme, T. Nordh, Y. Zou, J. Pettersson, U. Bexell, M. Boman, K. Edström and L. Nyholm, Energy Environ. Sci., 2017, 10, 1350-1357.

85 A. Paul, Low-angle polarized neutron and X-ray scattering from magnetic nanolayers and nanostructures, Springer Tracts in Modern Physics 273, Springer-Verlag, 2017, ISBN: 978-3-319-63223-0.

86 D. S. McPhail, J. Mater. Sci., 2016, 41, 873-903.

87 H. Okamoto, Bull. Alloy Phase Diagrams, 1989, 10, 69.

88 J. Sangster, J. Phase Equilib. Diffus., 2007, 28, 561-570. 